the bones of the face, destroyed the orbit, bled pro. fusely, and the poor fellow died.

I saw another case where the fungus occupied a Jarge part of the nostril, and projected into the pharynx; Sir Astley Cooper and I agreed to remove a part of it by ligature. The ligature came away, but there was so small a piece of fungus included in it, that it could scarcely be seen. It was composed entirely of vessels similar to the cauliflower excrescence of the uterus. The tumor grew again, and I have not heard the result, but $I$ have no doubt the patient died.

As for these malignant tumors, let them alone; from my own experience, I consider, from their having so broad a base, that any operation for them would do no good.

In the next lecture, Gentlepen, I shall mention other tumors that are liable to be confounded with polypus of the nose, and then I shall begin another subject.

\section{CASE OF RUPTURE}

\section{OF THE}

\section{LEFT VENTRICLE OF THE HEART,} By M. Bodington, Esq., Chesterfield.

On Friday, October 13th, at a quarter past one o'clock, p.m., I was sent for in haste to visit J. C., aged 70, who it was stated had been complaining of feeling unwell for a week or ten days, and in the course of the morning of a "stitch in the side," but had been just seized with violent pain in the chest. Upon arriving at his house, I found him sitting upon the bed, leaning forwards, with his elbows resting upon his knees, in which position, with some one pressing upon his chest, he was easiest. He complained of most excruciating spasmodic pain extending all over the chest. The pulse was very slow, and so feeble as scarcely to be perceptible at the wrist; the skin covered with a cold clammy perspiration; the countenance expressive of intense anxiety; in fact, he had every appearance of being in articulo mortis. I gave him some hot brandy and water, and applied hot bags of flour over the seat of pain. The pulse having slightly rallied and the severity of the pain not having abated, I left to procure some medicine, but returned immediately (with my partner Mr. Walker) and gave the following draught:-

Tincture of opium, forty-five minims ;

Compound spirit of ammonia, one draclim;

Camphor mixture, seven drachms ;

and ordered the feet to be put into hot water, with mustard in it; and to take a bolus composed of

Chloride of mercury, five grains;

Powdered opium, one grain;

Confection of roses, as much as required. To be repeated in half-an-hour, if the pain continues.

Three o'clock. The pain still as severe, and extends down each arm to the elbows. To repeat the draught immediately, and the bolus in an hour; and to apply a large blister to the chest, sponging it previously with tepid vinegar.

Six o' clock. My partner visited him, and found no alteration.

Half-past nine o'clock. He was again seen by my partncr, and complained then of the pain extending to the wrists, but seemed sumewhat more composed.
In less than ten minutes I was summoned again, and, upon arriving, found he had been dead about five minutes. After Mr. Walker left he had risen from the bed and walked across the room; a paroxysm of pain came on, and he died immediately.

\section{Post-mortem Examination, Eleven Hours after} Death.

Heart.-The pericardium was distended to the utmost with fluid and coagulated blood-in fact, had it not have been a particularly strong one, it mnst have been ruptured. The heart was of the usual size, but covered with an immense quantity of fat, and there was a general softening of its substance. Externally in the left ventricle, about three-quarters of an inch from the septum, were two lacerations, one communicating with the other; the larger of the two measured seven-eighths of an inch in length. Internally there was only one rupture in an oblique direction from below upwards; it would admit of the common-sized blowpipe. The walls of the ventricle were of the usual thickness, except in the situation of the rupture, where they were somewhat thinner. The walls of the right ventricle were exceedingly attenuated, very much more so in every part than at the point of rupture in the left. No trace of disease of the valves or of the arteries could be detected. Lungs, liver, intestines, and kidneys were perfectly healthy. Gallbladder contained eleven gall-stones, each of the size of a small nut, and some inspissated bile. The spleen presented a very remarkable appearance, the peritoneal covering being studded with minute elevated tubercles of a greyish white color, and at one point a number of them were concentrated together, forming a patch of the size of half-a-crown; upon cutting into this mass, it seemed like cartilage; in other respects the spleen was quite healthy.

$$
\text { REMARKS. }
$$

It is clearly evident that this was a case of rupture of the heart, occasioned by general softening of the muscular substance attendant upon fatty degeneration; it is also evident that the rupture must have taken place previous to my seeing the patient-consequently, as the pericardium became distended, so in proportion to that distention did the pain not only become aggravated, but extended gradually to the elbows, and immediately before death to the wrists. The blood being slowly poured into the pericardium, and coagulation taking place, the opening became blocked up with coagulum, and so prevented for the time further mischief; but as reaction took place, and under the excitement of walking across the room, the coagulum became displaced, hæmorrhage returned, and the man died instantly.

\section{SOLIDIFIED LUNG.}

Mr. Power presented a specimen of pneumonia in a child. The left lung sunk in water; the upper was the only part capable of respiration, and that portion, when separated from the remainder, was buoyant. There was extensive pleuritis at the same side with the inflamed lung. The history of the case was so far remarkable, that no complaint was made by the child up to thirty-six hours before its death.-Proceedings of the Pathological Society of Dublin, in Dub. Journ. of Med. Sci., Nov., 1813. 